\title{
The magnitude of differences in perceived general health associated with educational level in the regions of Spain
}

\author{
Enrique Regidor, Vicente Dominguez, Pedro Navarro, Carmen Rodriguez
}

\begin{abstract}
Study objective-To examine and compare the relation between inequalities in perceived general health and education in the 17 regions of Spain.

Design and methods-Data were taken from the 1993 Spanish Health Interview Survey. For each region we calculated the magnitude of inequality in perceived general health in association with educational level by a measure of association or effect and by a relative index of inequality. Both measures are odds ratios and were estimated by logistic regression. The first is an odds ratio associated with one year less education, while the second represents the inequality in perceived general health between those at the bottom and those at the top of the educational hierarchy.

Main results-The six regions with the highest relative indices of inequality also have the highest odds ratios associated with one year less education, and five of the six regions with the lowest relative indices of inequality have the lowest odds ratios associated with one year less education. Pearson's correlation coefficient between the odds ratio and the relative index of inequality is 0.94 .

Conclusions-Regional differences in levels of inequality in perceived general health are attributable exclusively to the effect of education on health and not to the distribution of the population among the different educational levels. It is not known why the magnitude of this effect of education on health varies from one area to another.
\end{abstract}

(F Epidemiol Community Health 1999;53:288-293)

Facultad de Medicina, Complutense

University of Madrid, Spain

E Regidor

V Dominguez

P Navarro

Department of Epidemiology, Ministry of Health,

Madrid, Spain

C Rodriguez

Correspondence to: Dr E Regidor, Department of Preventive Medicine and Public Health, Facultad de Medicina, Complutense University of Madrid,

Ciudad Universitaria- 28040,

Madrid, Spain.

Accepted for publication 5 October 1998

One of the most consistent observations in public health studies is that persons with a lower educational level have a higher mortality ${ }^{1-6}$ and a greater frequency of a wide range of health problems than those with a higher educational level. ${ }^{7-11}$ Another frequent finding is that the magnitude of the association between educational level and health varies among countries. Thus, several international studies of mortality, self reported health status, prevalence of chronic diseases or permanent disability have found important differences in the size of the relation between educational level and health in the different countries compared. ${ }^{12-15}$

Unfortunately, only a few countries have been compared in these studies, therefore it is difficult to make firm conclusions based on these findings. Nevertheless, two recent studies comparing 11 industrialised countries of Western Europe have detected greater inequalities in mortality and in subjective self reported health by educational level in the Nordic countries, where there is a longer tradition of egalitarian policies in the social, economic and health arenas. ${ }^{16} 17$ These results contradict some theories, according to which the size of the health inequalities will be larger in those areas where these types of policies are not applied. ${ }^{18-20}$

One explanation put forth for these findings is the possible existence of biases because of problems in data comparability. Thus, for example, the information on subjective perception of health comes from health interview surveys carried out in these countries, therefore it is highly probable that certain general characteristics of these surveys - whether or not they exclude certain population groups, whether or not proxies are used in the interviews, nonresponse rates, etc - may be very different among countries. ${ }^{16} 17$

Another possible explanation is that in societies where persons from different social strata have the same access to education, the educational level attained may depend less on socioeconomic circumstances during childhood and adolescence than on personal characteristics, such as health status and health related factors. Thus, the relation between educational level and health may be stronger in societies that are competitive, but have egalitarian educational policies, than in societies where individual characteristics are less important determinants of the educational level achieved than socioeconomic status. ${ }^{12} 1617$

It is also possible that the effect of education varies from one place to another for unknown reasons, which would make it difficult to justify differences in the magnitude of the association between education and various health indicators in different countries by some specific socioeconomic situation. One way to evaluate any of these hypotheses is to compare several countries or regions with similar socioeconomic policies and to make estimates based on the same data source. This strategy was followed in this study that compares (1) the magnitude of the association between educational level and self reported health status in each of the 17 regions of Spain using the same source of information, and (2) the size of health differences in each region that are related to educational inequality. 
Table 1 Number of interviews in each region and percentage of non-response regarding education

\begin{tabular}{lll}
\hline Region & $\begin{array}{l}\text { Number of } \\
\text { interviews }\end{array}$ & $\begin{array}{l}\text { \% Non-response } \\
\text { regarding education }\end{array}$ \\
\hline Andalucia & 1.991 & 0.60 \\
Aragon & 999 & 0.80 \\
Asturias & 779 & 2.20 \\
Balearic Islands & 799 & 0.25 \\
Canary Islands & 1.001 & 1.40 \\
Cantabria & 800 & 0.88 \\
Castilla-La Mancha & 999 & 0.70 \\
Castilla and Leon & 1.500 & 0.70 \\
Cataluña & 1.998 & 0.35 \\
Comunidad Valenciana & 1.495 & 0.30 \\
Extremadura & 1.000 & 0.40 \\
Galicia & 1.500 & 0.95 \\
Madrid & 1.985 & 0.65 \\
Murcia & 800 & 0.65 \\
Navarra & 800 & 1.40 \\
The Basque Country & 1.496 & 1.00 \\
La Rioja & 799 & 0.50 \\
\hline
\end{tabular}

\section{Methods}

SOURCE OF DATA

The data are taken from the 1993 Spanish National Health Survey carried out by the Ministry of Health. The sampling universe was made up of the non-institutionalised Spanish population. A representative sample of the population was obtained in each of Spain's 17 regions. The persons to be interviewed in each region were selected by multistage sampling with stratification of the first stage units. The first stage units - the municipalities - were randomly selected proportional to the size of the population, and the second stage units-the census sections-were selected by simple random sampling. Finally, subjects were selected by age and sex quotas. About $8.5 \%$ of the interviews were carried out after one or more of the previously selected subjects refused to answer the questionnaire. In most regions this percentage was similar or lower, except for Aragon, the Balearic Islands and Navarra, where there was a $20 \%$ refusal rate for first interviews. This study was limited to the population 16 years of age and older, as for younger persons the father or mother was interviewed, and the educational level was obtained only for the head of the family. Table 1 shows the total number of persons in this age group who were interviewed in each region.

To assure the proportional distribution of the sample by age, sex and educational levelgiven the importance of this proportionality in calculating one of the measures of health inequality used - the estimate of the weighting coefficients in each region was made a posteriori, by the procedure of stratifying after selection of the sample or after stratification. ${ }^{21}$ The reference population used for the calculation of these coefficients was the 1991 Population Census.

The question posed to obtain information on the subjective perception of health was: "In the last 12 months would you say your health has been very good, good, fair, poor or very poor?" This was converted into a dichotomous variable in this study by grouping the responses "very good" and "good" in one category and the responses fair", "poor" and "very poor" in another. This criterion was used to calculate the prevalence of "less than good" health.
Information on the educational level of the person interviewed was obtained by asking the question "What is your educational level?" The persons interviewed could choose among one of the following five alternatives: no education completed, education completed at 14-15 years, education completed at 16-19 years, subsequent education but not university level education, and university education. Education completed at $14-15$ years was considered first level education, and university education was third level education, while education completed at 16-19 years and subsequent education that was not university level was considered second level education. Thus, the classification of educational level used in this study was composed of the following four categories: no education completed, first level, second level and third level. The non-response rates to the question on education ranged from $0.2 \%$ to $2.2 \%$ (table 1 ).

MEASURES OF HEALTH INEQUALITIES

We compared inequalities in perceived general health associated with educational level using two indices of inequality proposed by Kunst and Mackenbach. ${ }^{1422}$ Firstly, for each region, we calculated the association between educational level and the prevalence of less than good health by an age and sex adjusted odds ratio. Educational level was quantified as mean number of years of education so that the estimates represent the odds ratio associated with one year less education. Persons with "no education completed" were assigned three years of education, "first level" was assigned five years, "second level", 10 years and "third level", 16 years. Persons with second level education were assigned a mean of 10 years of education because the available information was not sufficient to distinguish between the first phase (eight years of education) and second phase (12 years of education) of second level education.

Secondly, we calculated a relative index of inequality (RII) that takes into account the population distribution across socioeconomic groups. In calculating the RII we followed the method proposed by Pamuk. ${ }^{23}$ In accordance with this method a value is assigned to each educational group taking into account its relative position in the social hierarchy established in accordance with this variable. The only information needed is the population size of the educational groups. That is, if the highest educational group comprises $10 \%$ of the total population, the relative position of its members would be between 0 and 0.10 , the average being 0.05 . If the next highest educational group comprises $30 \%$, their hierarchical range is between 10 and $40 \%$, therefore, it is assigned an average of 0.25 , and so on. To assure that each region has enough people in each group of age, sex and educational level, this hierarchical range was calculated after grouping age into three categories. Under this index of inequality, each region's social hierarchy is the same length: the highest point has a value of 0 and the lowest has a value of 1 . As an increment of one unit equals the difference between the 


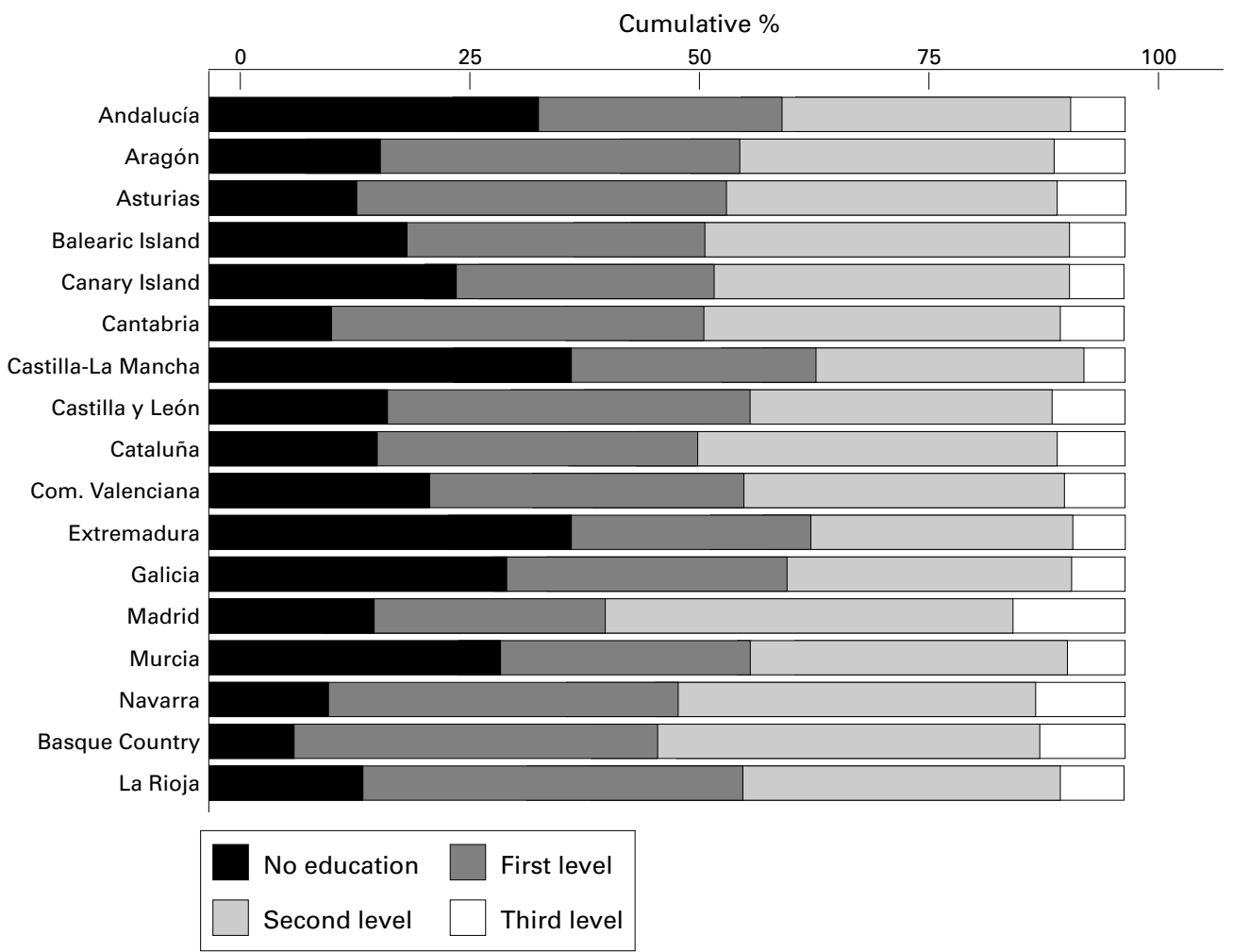

Figure 1 Distribution of the population among the different categories of educational level. Regions of Spain, 1993.

lowest (1) and the highest (0) point in the social hierarchy, the odds ratio estimated by this method represents the odds the prevalence of less than good health for those at the bottom of the socioeconomic hierarchy as compared with the odds the prevalence for those at the top.

In both cases, adjusted odds ratios were computed by logistic regression, using the statistical package SPSS for Windows. ${ }^{24}$ The calculation of these measures assumes a log-linear relation between education and perceived general health. This assumption was analysed by a test for deviation from linearity. It was assumed that the simplest deviation from linearity is a quadratic relation, therefore a quadratic term for the educational measure was including for this purpose in the regression

Table 2 Relation between perceived general health and education level. Prevalence of less than good perceived health, odds ratio (OR) and relative index of inequality (RII)

\begin{tabular}{llll}
\hline Region & $\begin{array}{l}\text { Prevalence } \\
(\%)\end{array}$ & $\begin{array}{l}\text { OR (95\% confidence } \\
\text { intervals)* }\end{array}$ & $\begin{array}{l}\text { RII }(95 \% \text { confidence } \\
\text { intervals) } t\end{array}$ \\
\hline Andalucia & 34.9 & $1.128(1.092,1.166)$ & $4.58(3.05,6.89)$ \\
Aragon & 30.5 & $1.074(1.024,1.126)$ & $2.28(1.29,4.04)$ \\
Asturias & 33.5 & $1.192(1.117,1.271)$ & $8.83(4.27,18.3)$ \\
Balearic Islands & 30.4 & $1.084(1.028,1.144)$ & $2.61(1.39,4.89)$ \\
Canary Islands & 36.0 & $1.073(1.026,1.122)$ & $2.51(1.45,4.32)$ \\
Cantabria & 28.2 & $1.104(1.042,1.170)$ & $3.43(1.76,6.69)$ \\
Castilla-La Mancha & 28.5 & $1.111(1.044,1.181)$ & $2.92(1.54,5.55)$ \\
Castilla and Leon & 34.1 & $1.153(1.105,1.202)$ & $5.48(3.44,8.73)$ \\
Cataluna & 26.2 & $1.152(1.109,1.196)$ & $5.59(3.66,8.56)$ \\
Comunidad Valenciana & 28.8 & $1.122(1.074,1.172)$ & $3.73(2.30,6.04)$ \\
Extremadura & 35.9 & $1.080(1.029,1.133)$ & $2.89(1.62,5.16)$ \\
Galicia & 37.7 & $1.116(1.073,1.161)$ & $3.43(2.19,5.38)$ \\
Madrid & 31.8 & $1.091(1.061,1.123)$ & $3.50(2.36,5.18)$ \\
Murcia & 28.8 & $1.071(1.013,1.133)$ & $2.25(1.14,4.43)$ \\
Navarra & 26.3 & $1.123(1.060,1.190)$ & $4.14(2.14,8.02)$ \\
The Basque Country & 27.8 & $1.099(1.056,1.143)$ & $3.49(2.16,5.62)$ \\
La Rioja & 28.8 & $1.080(1.018,1.145)$ & $3.04(1.58,5.87)$ \\
\hline \multirow{2}{*}{ Odds rati assiated }
\end{tabular}

$\star$ Odds ratio associated with one year less education. HOdds ratio of prevalence of less than good perceived health for those at the bottom of the educational hierarchy as compared with the prevalence for those at the top. equation. ${ }^{25}$ In the odds ratio associated with one year less education a departure from $\log$-linearity was seen in four regionsCatalunia, Comunidad Valenciana, Madrid and La Rioja-whereas in the RII this departure was seen only in the region of Murcia.

A larger RII, that is, a greater difference in the prevalence of less than good health between the high and low positions in the educational hierarchy, could be attributed either to the effect of one year less education or to educational inequality in itself. To test this, we first calculated Pearson's correlation coefficient between the odds ratio and the RII in each region, and second, we estimated the correlation coefficient between the RII and a measure of education inequality. In each region this measure of education inequality was calculated by linear regression where the dependent variable is the mean number of years of education, while the independent variable is the range or relative position that educational groups occupy with respect to the educational hierarchy. The regression coefficient obtained can be interpreted as the difference in the mean number of years of education between those at the bottom and those at the top of the educational hierarchy. ${ }^{26}$

\section{Results}

Figure 1 shows the distribution of the population according to educational level. Extremadura is the region with the highest percentage of population with no education $39.9 \%$, while Madrid is the region with the highest percentage of the population with third level education, $12.2 \%$

The prevalence of "less than good" health, shown in table 2, ranges from $26.2 \%$ in 


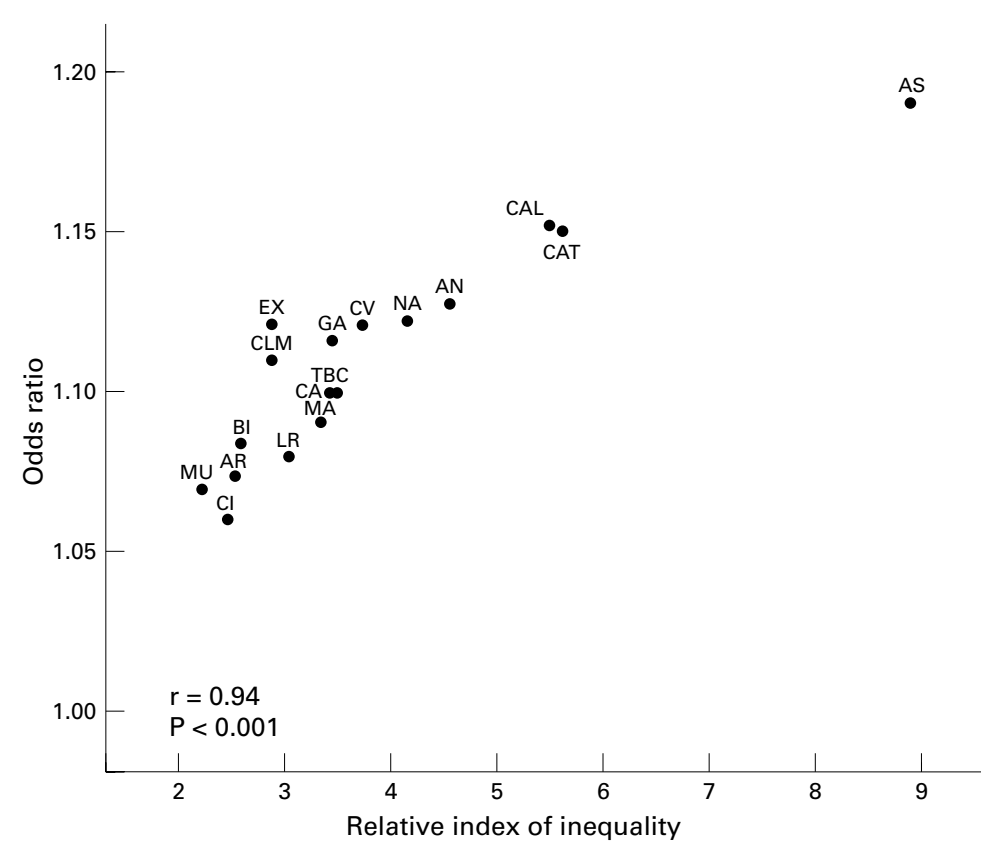

Figure 2 Relation between relative index of inequality and odds ratio associated with one year less education. Regions of Spain, 1993.

Catalonia to $37.7 \%$ in Galicia. Table 2 also shows the odds ratios associated with one year less education. The magnitude of the odds ratio ranges from 1.071 in Murcia and 1.073 in the Canary Islands to 1.192 in Asturia, 1.153 in Castilla y Leon and 1.152 in Catalonia. That is, the odds the prevalence of "less than good" health increased by $7.1 \%$ and $7.3 \%$ for each year less education in Murcia and the Canary Islands and by $19.2 \%, 15.3 \%$ and $15.2 \%$ in Asturias, Castilla y Leon and Catalonia, respectively.

The RII, that is, the odds ratio of the bottom versus the top of the educational hierarchy is shown in table 2. Murcia was also the region with the smallest magnitude (2.25), followed by Aragon (2.28) and the Canary Islands (2.51), while the highest values were for Asturias (8.83), Cataluña (5.59) and Castilla y Leon (5.48). The six regions with the largest RIIs also have the highest odds ratios associated with one year less education, and five of the six regions with the lowest odds ratios also have the smallest odds ratios associated with one year less education. Figure 2 shows this relation between RII and the odds ratios associated with one year less education $(r=0.94$; $\mathrm{p}<0.001$ ).

The difference in mean number of years of education between people occupying the highest and lowest point in the educational hierarchy ranges from 13.8 years in the region of Madrid to 11.0 years in the region of Castilla-La Mancha. Educational inequality was not related with the RII, Pearson's correlation coefficient was 0.06 .

\section{Discussion}

The relation observed in this study between perceived general health and educational level as well as the variation found in the magnitude of this association in the different regions of
KEY POINTS

- In all Spanish regions, the odds of the prevalence of less than good perceived health is higher among less educated people than among those who have more education.

- The size of educational differences in perceived health is relatively large in Asturias, Catalonia, and Castilla y Leon, and relatively small in Murcia, Aragon, and the Canary Islands.

- Regional differences in levels of inequality in perceived health are because of the effect of education on health, and not the distribution of the population among the different educational levels.

Spain are similar to the findings of studies carried out in this area in the developed countries.

Another finding of this study is that variations in the difference in perceived general health between those at the bottom and those at the top of the educational hierarchy or RII are attributable to the effect of education on health and not to the size of inequalities in education itself. The high correlation coefficient between the odds ratio associated with one year less education and the RII, on the one hand, and the absence of a relation between the estimates of inequalities in education and the estimates of RII, on the other, support this statement. Some theories assert that the size of income inequality in some countries is a determining factor in the magnitude of health inequalities; however, the results of this study, together with the results found in one of the studies carried out in 11 countries of Western Europe, show that this does not occur with education. ${ }^{17}$

In interpreting these results, certain considerations must be kept in mind. For example, in the Spanish National Interview Survey, the selection of the final sampling unit-the people-was made by age and sex quotas, thereby introducing a possible bias of unknown direction and magnitude. For example, in two of the three regions with the highest percentage of refusal of first interviews (Aragon and the Balearic Islands), the magnitude of the association between educational level and self reported health is low, whereas in the third region (Navarra) this magnitude is moderately high. The case of Asturias should also be noted, where the values obtained were clearly higher than in the rest of the regions, possibly because of an important bias in the selection of people. Because of this, the magnitude of the correlation coefficient between the two measures of health inequality will be overestimated.

Another consideration to be kept in mind is the possibility of a classification bias in educational level, as people with first phase (eight years of education) and second phase studies (12 years) of secondary level education were assigned to a single group (10 years). However, as there is a linear relation between educational level and perceived general health, the regression estimate using four or more 
educational level categories is similar, regardless of whether we use number of years of education or relative position in the educational hierarchy, as has been shown in other studies. ${ }^{16} 26$

With regard to linearity it should be mentioned that the model for the estimation of the odds ratio associated with one year less education deviates from linearity in four regions. In these cases the inequality index does not exactly reflect the true size of the inequalities in health. Nevertheless, the absence of a deviation from linearity in the logistic model is much more important in the RII as its calculation requires extrapolation to values that were not included in the model estimate, specifically, 0 and 1 , therefore the bias will be larger. Fortunately, inclusion of the quadratic term in the models that estimate the RII was only statistically significant in one region. In short, it is very improbable that these deviations from linearity would substantially change each region's position.

One argument that has been put forth to explain the variation in the size of the association between education and health refers to a selection bias by which the association between health and education is because of the fact that the educational level attained partly depends on health and health related factors. Although the hypothesis that selection bias is the basic mechanism giving rise to health inequalities has been rejected, the magnitude of this bias could vary among countries as a result of differences in their educational structures. ${ }^{16}{ }^{27}$ In any case, this cannot be the mechanism responsible for the variation in the size of the differences in health by educational level in the Spanish regions because they all have the same educational structure. With regard to this hypothesis it has also been postulated that in some societies where people from different social strata have equal access to education, the educational level attained may depend less on socioeconomic circumstances than on personal characteristics, including, naturally, health status. Oddly, the relation between education and health would be stronger in societies that are competitive but have egalitarian educational policies than in societies where individual characteristics are less important determinants of a person's level of health and wellbeing. ${ }^{12}$ This argument, which has been given as a possible explanation for the great inequalities in health found in the Nordic countries in the two aforementioned studies, ${ }^{16}{ }^{17}$ cannot be applied to this study of the Spanish regions because economic and social policies are the same throughout the country. However, the possibility cannot be ruled out that other factors, such as regional economic structures, could have some type of influence on the nature and strength of selection processes.

Another possible explanation of the variation in the size of the relation between education and perceived morbidity is based on the subjective nature of health information. ${ }^{15}$ That is, for historical, cultural or social reasons, the subjective perception of health may differ from one country to another, and this would be partly responsible for the socioeconomic variations in health. It is possible that this interpretation could also be applied to the results of this study, given the historical and cultural heterogeneity of the Spanish regions. In fact, the percentage of those interviewed in these regions who responded that they had less than good health varies between 25 and $35 \%{ }^{28}$

Another hypothesis that might be offered to interpret the results is that exposure to different risk factors for many diseases and injuries would cause a greater frequency of health problems and a greater prevalence of less than good health at lower educational levels. According to this theory, regional variations in the distribution of these risk factors in the different social strata would explain a good part of the variation in the magnitude of the association between perceived health and education. However, this is implausible because the distribution of the known risk factors by educational level in those regions with available information is quite similar. ${ }^{29-32}$

The variation in the size of the association between education and the subjective perception of health might also be attributed to certain economic circumstances that modulate that relation in the different countries or regions being compared. However, this also is not the most plausible explanation for the results of this study as the regions with less health inequality by educational level include both regions with high per capita income, Aragon, the Balearic Islands, and regions with low per capita income, Extremadura, the Canary Islands. Likewise, of the regions with greater inequality in health by educational level, Navarra and Cataluña have high per capita income while Andalucia and Castilla y Leon have low per capita income.

Finally, according to some theories we might also consider the possible influence of inequality in income on the relation between health and educational level. A recent study showed a relation in some Spanish regions between the size of the inequality in income and the size of the inequality in health. ${ }^{33}$ However, not all regions with smaller inequalities in income (Andalucia, Castilla-La Mancha, Castilla y Leon, and Extremadura) have smaller inequalities in health by educational level. Likewise, not all regions with larger inequalities in income (Navarra, Cataluña, Basque Country and La Rioja) have larger inequalities in health.

In summary, the results of this study and of recent international investigations have shown the importance of the effect of education on variations in the difference in perceived general health between those at the bottom and those at the top of the educational hierarchy, independently of the distribution of the population among the different educational levels. From the results of these studies it can also be inferred that the effect of education on health is universal. For reasons not sufficiently well understood, however, the magnitude of its effect varies among areas and over time within the same area. Thus it is necessary to carry out future studies to try to understand the contex- 
tual effects of the area of residence that can modify the relation between educational level and health.

Funding: none.

Conflicts of interest: none.

1 Feldman JJ, Makuc DM, Kleinman JC, et al. National trends in educational differentials in mortality. Am f Epidemiol 1989;129:919-33.

2 Valkonen T. Adults mortality nd level of education: a comparison of six countries. In: Fox J, ed. Health inequalities in European countries. Aldershot: Gower, 1989:142-72.

3 Doornbos G, Kromhout D. Educational level and mortality in a 32-year follow-up study of 18-year-old men in the Netherlands. Int $\mathcal{F}$ Epidemiol 1990;19:374-9.

4 Pappas G, Queen S, Hadden W, et al. The increasing disparity in mortality between socioeconomic groups in the
United States, 1960 and 1986. N Engl F Med 1993;329: 103-9.

5 Valkonen T, Martelin T, Rimpel A, et al S. Socio-economic differences in Finland 1981-1990. Helsinki: Central Statistical Office of Finland, 1993.

6 Sorlie PD, Backlund E, Keller JB. US mortality by economic, demographic, and social characteristics: The National Longitudinal Study. Am F Public Health 1995;85:949-56. $7 \mathrm{La}$ Vecchia C, Negri E, Pagano R, et al. Education, tion. F Epidemiol Community Health 1987;41:161-5.

8 House JS, Kessler RC, Herzog R, et al. Age, socioeconomic status, and health. Milbank $Q$ 1990;68:383-411.

9 Diez-Roux AV, Nieto FJ, Tyroler HA, et al. Social inequalities and atherosclerosis. The atherosclerosis risk in Communities Study. Am $\mathcal{F}$ Epidemiol 1995;141:960-72.

10 Bakke PS, Hanoa R, Gulsvik A. Educational level an obstructive lung disease given smoking habits and occupational airborne exposure: a Norwegian community study. Am f Epidemiol 1995;141:1080-8.

11 Gutierrez-Fisac JL, Regidor E, Rodriguez C. Trends in obesity differences by educational level in Spain. $\mathcal{F}$ Clin obesity differences by educa

12 Lahelma E, Valkonen T. Health and social inequities in Finland and elsewhere. Soc Sci Med 1990;27:257-65.

13 Lahelma E, Manderbacka K, Rahkonen O, et al. Ill-health and its social patterning in Finland, Norway and Sweden. Soc Sci Med 1994;38:517-24.

14 Kunst AE, Mackenbach JP. The size of mortality differences associated with educational level in nine industrialized countries. Am f Public Health 1994;84:932-7.

15 Kunst AE, Geurts JJM, Van den Berg J. International variation of socio-economic inequalities in self-reported health. 7 Epidemiol Community Health 1995;84:932-7.

16 Mackenbach JP, Kunst AE, Cavelaars EJM, et al, EU Working Group on Inequalities in Health. Socioeconomic inequalities in morbidity and mortality in Western Europe: a comparative study. Lancet 1997;349:1655-9.

17 Cavelaars AEJM, Kunst AE, Geurts JJM, et al. Inequalities in self-reported morbidity by educational level: a comparison of 11 Western European countries. If Epidemiol Community Health 1998;52:219-27.

18 Wilkinson RG. National mortality rates: the impact of inequality? Am f Public Health 1992;82:1082-4.

19 Wilkinson RG. Divided we fall. The poor pay the price of increased social inequality with their health. BMF 1994; 308:1113-14

20 Davey Smith G, Egger M. Socioeconomic differentials in wealth and health. Widening inequalities in health - the legacy of the Thatcher years. BMf 1993;307:1985-6.

21 Levy PS, Lemeshow S. Sampling for health professionals. Belmont, California: Lifetime Learning Publications, 1980: $124-8$.

22 Kunst AE, Mackenbach JP. Measuring socio-economic inequalities in health. Copenhagen: World Health Organization, 1994.

23 Pamuk ER. Social class and inequality in mortality from 1921 to 1972 in England and Wales. Popululation Studies 1985;39:17-31.

24 Norusis MJ. SPSS for Windows. Advanced statistics, Release 6.0. Chicago: SPSS Inc, 1993.

25 Clayton D, Hills M. Statistical models in epidemiology. Oxford: Oxford University Press, 1993:249-60.

26 Kunst AE, Cavelars AEJM, Groenhof F, et al, EU working group on socio-economic inequalities in health. Socioeconomic inequalities in morbidity and mortality in Europe: a comparative study. Rotterdam: Erasmus University, 1996.

27 West P. Rethinking the health selection explanation for health inequalities. Soc Sci Med 1991;32:373-84.

28 Regidor E, Gutiérrez-Fisac JL, Rodríguez C. Indicadores de salud. Tercera evaluación en España del Programa regional europeo Salud para todos. Madrid: Ministerio de Sanidad y Consumo, 1995:43-6.

29 Gobierno Vasco. Encuesta de Salud de la Comunidad Autonoma Vasca. Vitoria: Departamento de Sanidad y Consumo, 1987

30 Generalitat Valenciana. Encuesta de Salud de la Comunidad Valenciana 1990-91. Valencia: Conselleria de Sanitat i Consum, 1993.

31 Tormo MJ, Navarro C. Factores de riesgo cardiovascular en la región de Murcia, 1992. Murcia: Consejería de Sanidad y Asuntos Sociales, 1995.

32 Generalitat de Catalunya. Departament de Sanitat y Seguretat Social. Enquesta de Salut de Catalunya, 1994 Barcelona: Servei Català de la Salut, 1996,

33 Regidor E, Navarro P, Domínguez V, et al. Inequalities in income and longterm disability in Spain. analysis of recent hypotheses using cross sectional study based on individual data. BMF 1997;315:1130-5. 